\section{Campaigning for Chagas disease}

\section{Energized individuals have worked hard to raise awareness. But politicians have not always listened.}

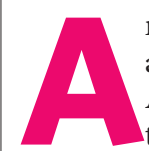
audience at screen three in Buenos Aires's Gaumont cinema in Argentina. "I am a medical student and I know nothing about this," says one young woman. "I live in Capital Federal - I was born here - and I have never heard a government talk of Chagas disease or heard any discussion about it," says another, who is then advised where she can get tested by the local Médecins Sans Frontières (MSF) coordinator, María Tinelli. Tom Ellman, who runs the organization's Bolivia programme, explains the purpose of the documentary film that the audience has just watched. "We don't understand why there is so much silence while there are so many people with the disease. We need a popular movement." He has in mind something akin to the community activism that first brought attention to AIDS.

Fighting Chagas disease requires coordinated and sustained pressure at every level. The disease has top-down, transnational programmes, one of which - the Southern Cone Initiative has been in existence for nearly 20 years. Much progress has been made this way; however, most experts comment that success has been patchy and deadlines have been missed. In 1998, the World Health Assembly (WHA), which is the policy-setting body of the World Health Organization (WHO), declared its commitment to eliminating the transmission of Chagas disease by the end of 2010 - a goal that it considered "technically feasible given appropriate political, technical and economic support". In 2007, the goal was renewed. Today it seems absurd.

So what is going wrong? One comment is that the Pan American Health Organization is too diplomatic to be open about Chagas disease projects that have not worked. Another is that the targets generated at the meetings of the transnational initiatives barely carry the gravitas of 'guidelines'. They are left for a few motivated individuals to work into the peculiar structures of decentralized and often chaotic health-care systems, which usually have little or no money set aside for this purpose.

Thus the question facing policymakers is how to strengthen the top-down initiatives microphone is passed around the and, at the same time, foster grassroots projects that meet real needs and put pressure on politicians. Again, this faces an intrinsic difficulty. The argument for bottom-up development often rests on the premise that individuals understand their own needs better than anyone else. Many of those with Chagas disease, however, do not know that they are infected, and those at most risk have typically never heard of the disease.

\section{Props for public outreach}

Ellman and his team are engendering grassroots enthusiasm in Bolivia, which is a good place country and because it has a strong history of community activism. The MSF campaign in to start, both because it is the worst affected
Bolivia is based around education; it includes street fairs where local residents can, for example, search for plastic vectors in a foam wall.

Last year the team drove from town to town, through all of Bolivia's departments where Chagas disease is endemic, in a bus full of props, unloading and educating. He says that drumming up local awareness is a balancing act. "On the whole, you're treating people who feel healthy with drugs that will give about $40 \%$ of them mild side effects like allergic skin reactions, so there are barriers to creating demand," he explains. "But we also don't want to spur levels of demand that the state can't meet, and demotivate the providers."

A couple of other notable grassroots efforts are based in wealthy countries that have seen recent rises in the numbers of Chagas disease cases. Spain, for example, is the home of the Association of Friends of People with Chagas Disease (ASAPECHA), which was founded in 2008. ASAPECHA holds events to raise awareness in Barcelona, where many Bolivian immigrants live, and also acts as a lobby group for patients' rights.

Much patient outreach in the United States is down to Sheba Meymandi. She runs the only centre of excellence for Chagas disease in the United States, and the only location where

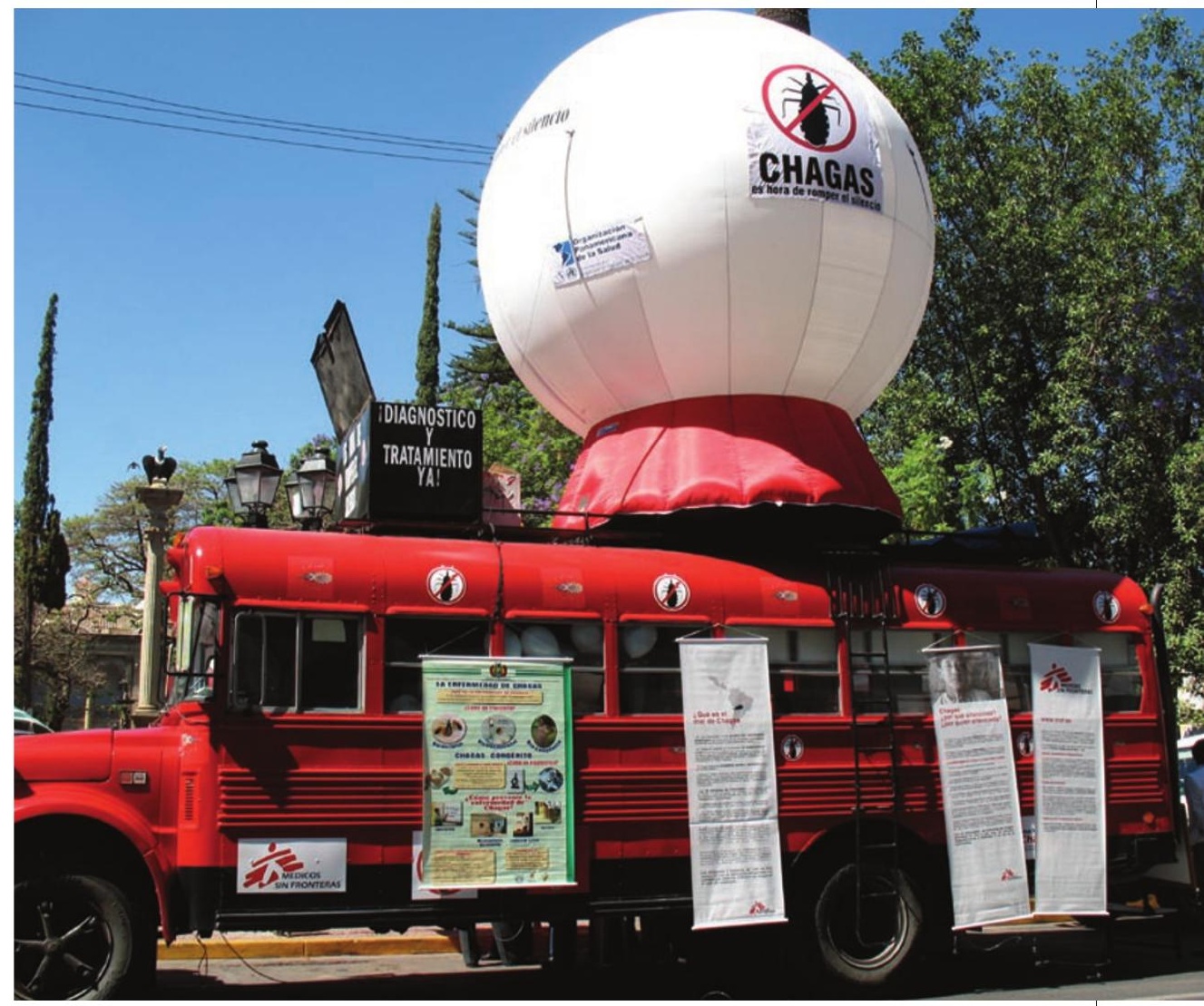

The Médecins Sans Frontières Chagas Bus, which travelled throughout Bolivia in 2009. 


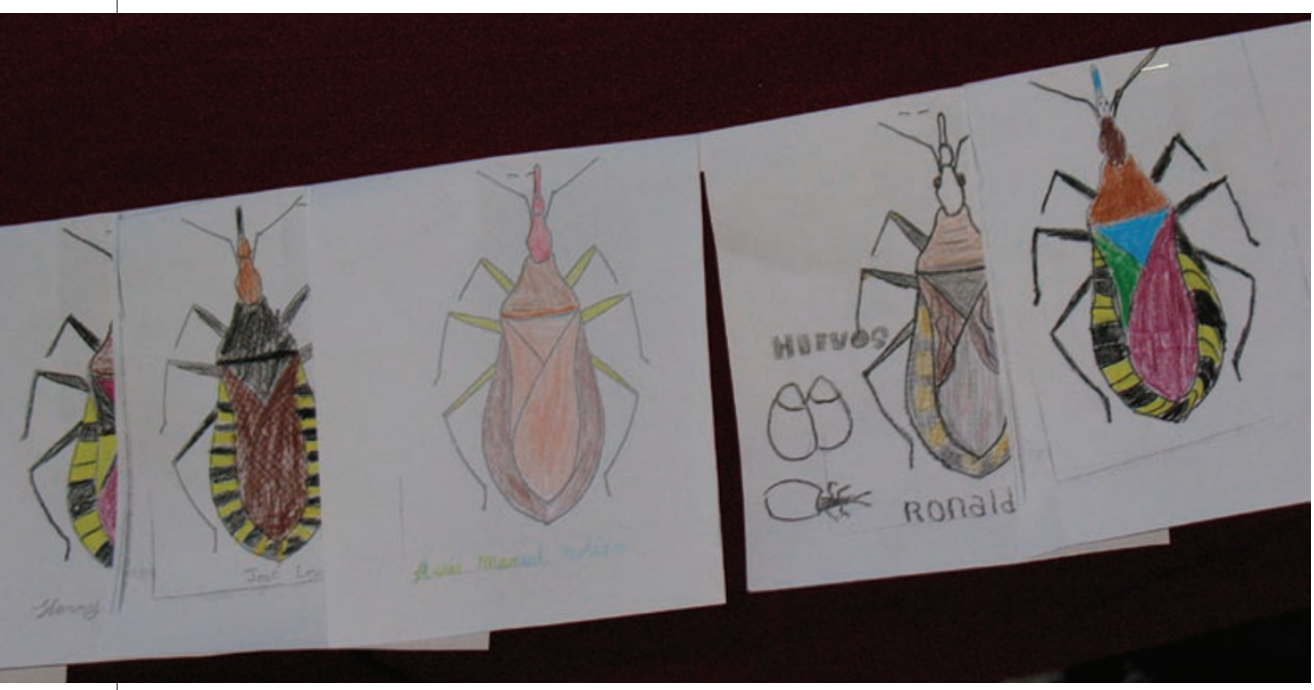

Drawings by children from Villa Montes in the southeastern Bolivian Chaco.

patients can receive drugs directly instead of having their doctor make a request to the Centers for Disease Control in Atlanta, Georgia.

Meymandi has had to pay for a large part of her work herself. The centre that she runs in the San Fernando Valley of northern Los Angeles in the United States has tested 1,500 Latin American immigrants, most of whom originate from Mexico or El Salvador. Every 2 weeks she accompanies 'promotores' volunteer health advocates from the local community - to a different church, handing out fliers and setting up a testing clinic in the lobby. This outreach programme seems to be working. Beforehand, few of those who tested positive for Chagas disease when they gave blood would seek treatment. Since targeting the immigrant population in this way, every person who has tested positive at their local church has later attended Meymandi's clinic.

Meymandi has found that $15 \%$ of heartfailure patients of Latin American origin in northern Los Angeles have Chagas disease. In January this year she came across two cases of Chagas disease in white Americans, aged 10 and 18 years, respectively, who had never travelled outside the United States or received blood transfusions. These cases confirm that vectorial transmission occasionally occurs in the United States. Despite this, Meymandi still has difficulty in getting the attention of politicians.

Part of the reason for this might be cultural. "I have tonnes of gay friends who are gay activists but none of my Hispanic friends would even think about going out and demanding something for their community." It is also partly because Chagas disease is hard to disentangle from the hot politics of illegal immigration in the United States, even though most of Meymandi's patients are in the country legally. "My success rate with politicians here in Los Angeles has been horrific. You would think that some young congressmen with a large Hispanic constituency would be interested but they don't want to touch it."
Patricia Dorn, who is a professor at Loyola University in New Orleans, has also met this kind of reception. After presenting a research proposal to study Chagas disease among pregnant women in the United States in 2006, she was asked by a member of the grant-giving panel, "If you put aside the immigrant population, is this important to others?" Dorn did not receive a grant for the project, but the same panel did give her money to send students on a field course to Central America.

\section{Governmental roles}

Community will is important, but health experts say national governments need to step in with funding and legal reforms. Argentina passed a law in 2007 that makes it illegal to avoid hiring someone because they are infected with Trypanosoma cruzi. Until recently, many employers in the country would run a series of medical tests, including a test for Chagas disease, before taking on new recruits. They would use the results to discriminate against those who might develop serious complications of the heart and gut. Because a positive test for T. cruzi infection indicates a 30\% chance of such symptoms developing, the discrimination affected many people whose work would never have been interrupted by their infection. This law still needs to pass through one more stage of the legal process.

The provision of drugs also lacks national coordination. In 2006, Evo Morales, the president of Bolivia, passed a decree guaranteeing all Bolivians the right to free diagnosis and treatment for Chagas disease (although few are aware that it exists); however, less than half of those diagnosed during a national campaign that finished in 2005 have received treatment. Benznidazole, which is the preferred drug to treat Chagas disease, is not licensed in Bolivia in the form that it is produced today, even though MSF can give it out. It is also not available in the United States.

Benznidazole was manufactured by Roche until 2003, when the production license was

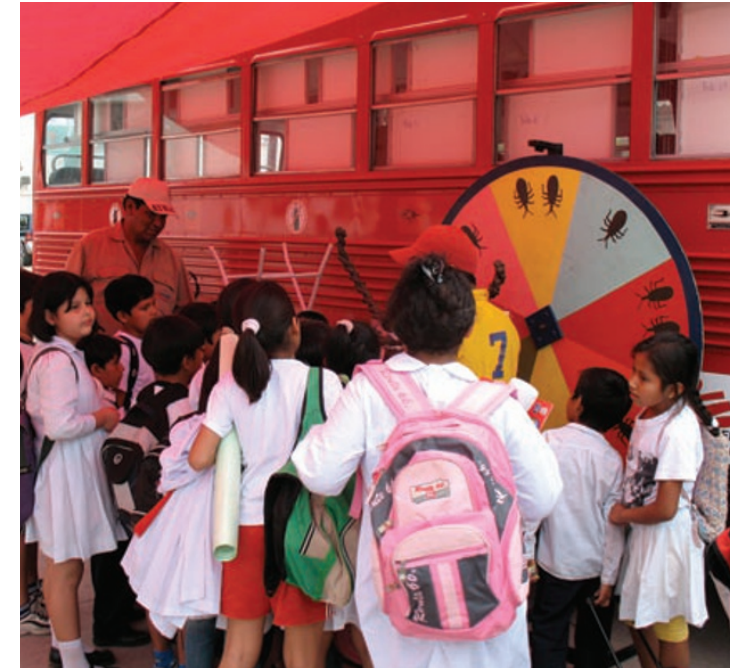

Local children play a game about Chagas disease.

transferred to the Pharmaceutical Laboratory of Pernambuco (LAFEPE), a Brazilian government facility. In October 2010, the only benznidazole in Bolivia - a batch made by Roche - will expire. "Not only is there just one manufacturer of this drug," says Ellman, "but the Brazilian lab depends on just one manufacturer of the drug's raw ingredient a company in Taiwan."

Rich countries and non-governmental organizations could help the situation, but Chagas disease is not a fashionable affliction of the needy. Of the US $\$ 2.5$ billion invested in research and development into neglected diseases over the past decade, just $0.5 \%$ or about US $\$ 10$ million went to Chagas disease, little of which found its way into diagnostics research, says Eric Stobbaerts, who is director for Latin America at the Drugs for Neglected Diseases Initiative (DNDi). The Bill \& Melinda Gates Foundation is not funding Chagas disease programmes, and the Institute for OneWorld Health began a Chagas disease project only to find itself overcommitted elsewhere, according to Jim McKerrow, a researcher at the University of California, San Francisco, who is still working on that project.

So there is much to do. Moreover, a lot rests on the shoulders of an energized few. There are signs that this community is getting savvier, and it is in some ways helpful that Chagas disease is having an impact in countries where international public-health priorities are set and funding decisions are taken. After failing to find a place on the agenda last year, Chagas disease will get a mention at the WHA in 2010. A resolution passed at the meeting might grant the citizens of all WHOmember countries the right to free diagnosis and treatment for the disease, and make those countries more accountable for the accuracy of the statistics that they provide. That is a necessary step if Chagas disease transmission really is going to be stamped out.

Anna Petherick 